\title{
Demographic consequences of mitigating strategies in planktonic invertebrates facing global browning of freshwater ecosystem
}

\author{
Małgorzata Adamczuk ${ }^{1}$ (D)
}

Received: 29 July 2020 / Accepted: 2 February 2021 / Published online: 23 February 2021

(c) The Author(s) 2021

\begin{abstract}
Recently, it has been reported that freshwater browning has less effect on planktonic invertebrate abundances than would be expected from current knowledge regarding of the biochemical activity of dissolved organic matter. It may be that the weak responses of whole communities to browning are masked because the individual mitigating strategies of community components have disparate demographic consequences. To examine the above hypothesis, individual-, population- and community-level responses of freshwater invertebrates to varying concentrations of terrestrial dissolved organic matter (tDOM) were investigated. Common cladocerans of the Chydoridae family, Chydorus sphaericus and Acroperus harpae, were used in the experiment which revealed that species employed different strategies to cope with tDOM. C. sphaericus maintained high production of asexual offspring at the cost of individual body growth, so any decreases in the population sizes were not observed. A. harpae, conversely, invested mainly in the production of resting eggs and increased survivability, which resulted in smaller populations. Invertebrate communities showed similar resilience and temporal stability across tDOM concentrations. Therefore, the influence of tDOM was apparently negligible at community level, since the effects of the mitigating strategies of the two species complemented one another. This experiment showed that symptoms of freshwater browning might be difficult to observe at population and community level due to effective mitigating strategies performed at the level of individuals. The effects of browning on freshwater invertebrates might be better considered in the context of alterations in the demographic rates together constituting life-cycle strategies to maintain species survival.
\end{abstract}

Keywords Dissolved organic matter $\cdot$ Reproduction $\cdot$ Trade-offs $\cdot$ Population $\cdot$ Community $\cdot$ Stability

\section{Introduction}

Studies conducted in the past decades have revealed the browning of surface waters followed by significant increases in organic carbon concentration (Roulet and Moore 2006). These trends in water colour result from changes in land management (Meyer-Jacob et al. 2015) coupled with climate changes (Larsen et al. 2011), which produce increasing amounts of dissolved organic matter of terrestrial origin being delivered to aquatic ecosystems. This type of organic matter is a mixture of aromatic and aliphatic hydrocarbon structures, with various attached functional groups, that create heterogeneous aggregates weakly biodegradable in

Małgorzata Adamczuk

malgorzata.adamczuk@up.lublin.pl

1 Department of Hydrobiology and Protection of Ecosystems, University of Life Sciences, B. Dobrzańskiego 37,

20-262 Lublin, Poland water (Thurman 1985). The current rate of browning of freshwater ecosystems is without precedent due to climatic perturbations in temperature and precipitation that have implications for terrestrial productivity and control the hydrological transport of organic matter within lake catchments (Weyhenmeyer et al. 2016). Observed lake browning processes are expected to have global effects, such as changes in the carbon cycle (Battin et al. 2009), deterioration of drinking water quality caused by elevated concentrations of organic matter (Dadi et al. 2015), and increasing costs of water treatment because of the formation of toxic byproducts during disinfection (Galapate et al. 2001). The other effects of lake browning stem from the influence of organic matter concentrations on the abiotic conditions of aquatic ecosystems. The easily-observed effects result from light attenuation caused by humic compounds. Thus, the occurrence of elevated concentrations of organic matter hampers photosynthetic processes (Karlsson et al. 2009) and consequently reduces lakes' primary production (Jones 
1992) as well as triggers the expansion of trophically related communities utilizing organic matter as the primary source of energy (Jansson et al. 2007). Moreover, elevated concentrations of organic matter stimulate oxygen depletion (Brothers et al. 2014) as a result of higher respiration rates, the promotion of photo-oxidation, and the suppression of released photosynthetic oxygen (Lindell et al. 2000). Oxygen depletion in freshwaters typically has biogeochemical consequences, including internal phosphorus loading (Mortimer 1942) and reduced organic matter mineralization (Fortino et al. 2014), as well as significant ecological consequences, including decreases in the biological richness and diversity of an ecosystem (Townsend et al. 1992). Other aspects of the influence of tDOM on aquatic ecosystems stem from the biochemical characteristics of its components. Some papers report that the presence of humic substances exert chemical and oxidative stress on aquatic animals (Meems et al. 2004; Timofeyev et al. 2004), they may also induce hormone-like effects manifested in the dysfunctional growth and reproduction of invertebrates and vertebrates (Höss et al. 2002; Lutz et al. 2005).

Although numerous laboratory experiments have demonstrated that the addition of dissolved organic matter alters the physiological traits and life histories of invertebrates (Minguez et al. 2020; Nova et al. 2019), the influence of browning on the abundance dynamics of invertebrate populations and communities is rarely observed in field studies. Observation of freshwater ecosystems suggests that browning might have a neutral or slightly positive influence on the population sizes of common species of invertebrates (Kelly et al. 2016), whereas its influence on ecosystem service delivery is negligible (Williamson et al. 1999). To explain the above discrepancies, the individual-, population-, and communityresponse of freshwater invertebrates to concentration of tDOM were investigated. Although such multidimensional research into species' response might lead to better comprehension of the consequences of the relationships between organisms and their environments (i.e. Adamczuk and Mieczan 2015), they are actually quite rare. For the experiment, two taxa of common cladocerans were selected: Chydorus sphaericus (O. F. Müller, 1776) emend. Frey 1980 and Acroperus harpae (Baird, 1834). These species are representative of the Chydoridae family and occur across a broad geographical range. A. harpae is widely distributed in Europe and $C$. sphaericus represents a complex of cryptic species (Belayeva and Taylor 2009) widely distributed in the Palearctic, some regions of Africa, Australia, and South America (Smirnov 1996). A. harpae and C. sphaericus often co-occur in the regions of their geographical coverage. Acroperus' distribution is related to $\mathrm{pH}$ and potassium concentration (Nevalainen et al. 2011a) and is reported to occur in less productive and well oxygenized lakes (Bos and Cumming 2003). C. sphaericus is able to live and reproduce across a wide $\mathrm{pH}$ spectrum and occurs under a wide range of environmental conditions, as it settles in water bodies with different levels of calcification, salination, and nutrients concentration and is able to survive low concentrations of dissolved oxygen (Brucet et al. 2009); thus, it is characterized as eurytopic, pioneering, and highly adaptive (Smirnov 1996). Both species are cyclic parthenogens, able to produce a maximum of two parthenogenetic eggs (Smirnov 1996), and demonstrate environmental sex determination (Nevalainen et al. 2011b). It may be hypothesized that the species display disparate responses to browning due to their different ranges of ecological tolerance, however both species experience costs of mitigating the effect of tDOM at the level of the individual organism. The research question is what are these costs at individual level and how are they manifested at higher levels of organisation (population and community). Answering to the above question may provide a more nuanced view of the response of invertebrates to the browning of freshwater ecosystems.

\section{Materials and methods}

\section{Experimental system}

tDOM was obtained from extracts of bluegrass, Poa pratensis L. This organic matter from a terrestrial plant species was used to produce a mixture of organic compounds similar to those entering water ecosystems. Bluegrass leaves were ground into coarse fragments, saturated with distilled water, and constantly aerated for 3 months at $25^{\circ} \mathrm{C}$. To detach the dissolved organic matter, i.e. the mixture of organic compounds smaller than $0.45 \mu \mathrm{m}$ in diameter (Thurman 1985), leachate was extracted sequentially through a series of sieves and filters, finally passing through a $0.45 \mu \mathrm{m}$ membrane. The extract was stored in sterile bottles at $4{ }^{\circ} \mathrm{C}$ and re-filtered through a $0.45 \mu \mathrm{m}$ membrane before use. Concentration of tDOM was expressed as the concentration of organic carbon (Leenheer and Croué 2003) determined in the filtered extract using a PASTEL UV spectrophotometer (Secomam, France). The experiments were based on treatments with six different concentrations of tDOM in the experiments: $0,5,10,15$, 25 , and $50 \mathrm{mg} / \mathrm{L}$. An appropriate volume of leaf extract was added to COMBO medium (Kilham et al. 1998) in order to obtain the above concentrations of tDOM. As addition of organic matter may cause oxygen depletion, oxygen concentration in each treatment was checked to design whether experimental treatments need to be aerated throughout the experiment. Eventually, the treatments were not aerated, since they displayed similar oxygen concentration suggesting that amount of oxygen involved in mineralization of organic matter was passively replenished from the air. Both A. harpae and C. sphaericus were cultured at $22^{\circ} \mathrm{C}$, in $16 \mathrm{~h}$ 
light and $8 \mathrm{~h}$ dark photoperiod, fed copiously with instant algae, and transferred to fresh medium every 4 days.

\section{Experimental environment}

Prior to adding the animals, physical and chemical analysis of the treatment was conducted to determine how the addition of tDOM impacts the medium. The concentration of total suspended solids (TSS), total dissolved solids (TDS) and surfactants (SUR), chemical oxygen demand (COD), biochemical oxygen demand (BOD), $\mathrm{pH}$, and electric conductivity (EC) were measured $24 \mathrm{~h}$ after $\mathrm{tDOM}$ was added. All measurements were made using a PASTEL UV spectrophotometer (Secomam, France) and a YSI 556 MPS multiparametric probe. Linear regression was used to explore the relationships between the above parameters and tDOM concentration.

\section{Response of individuals to tDOM concentrations}

The aim of this experiment was to assess how the addition of tDOM affects invertebrates' individual traits. Thus, 30 mothers with asexual eggs were randomly separated from the laboratory culture. Each mother was transferred to a $50 \mathrm{~mL}$ jar. After she had released the offspring, the mother was removed from the jar and one neonate was selected for the experiment, transferred to new media and reared separately (one individual per $50 \mathrm{~mL}$ jar). The rest of the neonates $(<12 \mathrm{~h})$ from each brood were anaesthetised and measured to assess individual somatic growth. Individuals were observed daily to assess survival and production of broods. These observations were continued until their natural death. The outcomes of the observations were used to construct an integral projection model (IPM) describing alterations in individual traits under different tDOM concentrations. This model was selected because it is widely employed to forecast population dynamics and is applied to populations in which an individual trait depends on a continuous variable (Easterling et al. 2000). The general equation of the model:

$n_{t+1}\left(x^{\prime}\right)=\int_{\Omega} K\left(x^{\prime}, x\right) n_{t}(x) d x^{\prime}$

describes the changes in population size distribution, $n$, from time $t$ to $t+1$ using a population projection kernel, $K(x$, $x$ ), integrated over the set of all possible sizes, $\Omega$. The IPM was constructed to display transitions from a daily census $(t)$. The four kernels describing all daily transitions were survivability, $S(x)$, growth, $G\left(x^{\prime} \mid x\right)$, reproduction, $R(x)$, and an offspring size distribution $r\left(x^{\prime} \mid x\right)$. Survivability $(S)$ described the probability that an individual with size $x$ survived from time $t$ to time $t+1$. Survivability data were binomial with possible outcomes of either death (0) or survival
(1), thus they were modelled using a logistic regression. Daily growth $(G)$ described the probability that an individual grew from size $x$ at time $t$ to size $x^{\prime}$ at time $t+1$. Reproduction $(R)$ was defined as the product of the probability of carrying eggs $(p)$, and brood size $(f)$, by individuals of size $x$ at time $t$. The probability of carrying eggs $(p)$ was estimated by dichotomizing the presence of eggs in the brood pouch into zeroes ( 0 eggs) and ones ( $>0$ eggs) and was modelled with a logistic regression. Brood size $(f)$, the total number of new-born individuals reproduced by individuals of size $x$ at time $t$, was obtained during the experiment and was fitted using linear regression. Offspring size distribution $r\left(x^{\prime} \mid x\right)$ described the probability of obtaining offspring with size $x^{\prime}$ at day $t+1$, given the maternal size at day $t$, and was fitted using linear regression. The procedures for each kernel are explained in detail in Supplemental Material Appendix S1. The resulting final equation of the model was:

$n_{t+1}\left(x^{\prime}\right)=\int_{\Omega}\left[S(x)+G\left(x^{\prime} x\right)+p(x)+f(x)+r\left(x^{\prime} x\right)\right]\left(n_{t}(x) d x^{\prime}\right.$

All models were tested for each individual trait, including the additive effects of tDOM concentration $(M)$. The effects of age structure $(A)$ on individual traits were also explored (Fig. S1, S2 in Supplemental Material Appendix S2). However, size and age showed a significant correlation $(C$. sphaericus: $r_{x-A}^{2}=0.706 ; A$. harpae: $r_{x-A}^{2}=0.722$ ), thus $A$ in interaction with $x$ was included in the model. As a result, a composite IPM was created, whereby the kernels (survival probability $S$, growth $G$, probability of carrying eggs $p$, brood size $f$, and offspring size distribution $r$ ) were functions of body size $(x)$, size and age $(x: A)$, and tDOM $(M)$, after it had been confirmed that $M$ was only weakly correlated with $x$ and $A$ (C. sphaericus: $r_{x-M}^{2}=0.012, r_{A-M}^{2}=0.017$; A. harpae: $\left.r_{x-M}^{2}=0.008, r_{A-M}^{2}=0.022\right)$. Finally, interactions between $M$ and $x$, and $M, x$, and $A$ were also included. The most complex model was thus:

$$
\begin{aligned}
y(x, x A, M) & =\beta_{0}+\beta_{1} x+\beta_{2} M+\beta_{3} x: A \\
& +\beta_{4} M: x+\beta_{5} M: x: A+\varepsilon_{\text {res }}
\end{aligned}
$$

and 96 models nested within this model were fitted. To reduce the risk of finding spurious effects and improve prediction accuracy, the averaged model was built on the basis of the best models (Raftery et al. 1997; Yang 2007). The Akaike information criterion (AIC) was applied to select the best models, i.e. models fulfilling the criterion of delta AIC $\leq 2$ (Table S1-S5 in Supplemental Material Appendix S3). A conservative zero method was used to build the averaged model; in this method, zero was assigned to the parameters not present in the model (Grueber et al. 2011). It was possible to use the conservative zero method since the differences between the log and the logit link function were negligible in the IPM model. 


\section{Response at population and community level to tDOM concentrations}

Experimental populations were established to find the population response, expressed by changes in population size and reproduction, to the range of $\mathrm{tDOM}$ concentrations. The initial population was 20 individuals of each species. The populations were cultured together in $700 \mathrm{~mL}$ glass jars containing COMBO media enriched with $\mathrm{TDOM}$, with the addition of 1-hexadecanol to prevent animals becoming trapped in the water surface film (Desmarais 1997). Each experimental treatment was established in three replicates. The experiment lasted for 100 days and population measurements were made every 4 days. Prior to measurements being taken, each experimental culture was bubbled for several seconds to prevent patchy distribution of animals in the jars. Then, $100 \mathrm{ml}$ of the experimental culture was passed through a $30 \mu \mathrm{m}$ sieve to separate the animals. Separated animals were anaesthetized with carbonated water to prevent egg rejection and then preserved with Lugol's solution. The size of each population (expressed as the number of individuals per treatment) was estimated using a stereomicroscope. The number of asexual and sexual females in reproduction was counted to obtain the reproduction $\left(F_{\text {asex }}, F_{\text {sex }}\right)$ value of each population. $F_{\text {asex }}$ and $F_{\text {sex }}$ were estimated as the percentage quotient of the number of either embryo-bearing parthenogenetic individuals or ephippial females and the total number of individuals. Differences in population sizes, $F_{\text {asex }}$ and $F_{\text {sex }}$ across treatments were determined by repeated measures analysis of variance with tDOM concentration as within-subject factor and time of the experiment ( 25 measures between 4 and 100th day of the experiment) as level of repeated measures.

To establish the community response to tDOM concentrations, the functional stability of the community was calculated for each treatment. Functional stability was expressed in two ways: resilience and temporal stability. Resilience $(R)$ was measured as the slope of the log-transformed difference between the community reared in the treatment with additional tDOM $(5-50 \mathrm{mg} / \mathrm{L})$ and the community reared in the environment without tDOM. Temporal stability $(D)$ was calculated as the inverse of the standard deviation of the residuals around the resilience (Dakos et al. 2012). Resilience and temporal stability were calculated from community level data. $R$ s and $D$ s of $C$. sphaericus and A. harpae populations were also calculated to find the relationships between each population and community across tDOM concentrations. These relationships were produced using Spearman's rank correlation. Differences in $R$ s and $D$ s of communities and populations were determined by ANOVA, followed by pairwise comparisons using Tukey's HSD. Rs and $D$ s were correlated with each other (Spearman's rank correlation) to estimate differences in the dimensionalities of functional stability.

\section{Results}

\section{Experimental environment}

The addition of tDOM not only increased the concentration of organic carbon but also significantly altered the chemical characteristics of experimental treatments. Significant increases in TDS, TSS, SUR, COD, BOD, and EC were observed associated with tDOM concentration, and the linear regression showed strong correlations between the values of the above variables and amounts of $\operatorname{tDOM}\left(r^{2}>0.90\right.$, $p<0.001$ for each correlation, Fig. 1a-e). Addition of tDOM did not affect $\mathrm{pH}\left(r^{2}=0.06, p>0.1\right)$, and this variable was quite stable in all the experimental environments (Fig. 1f).

\section{Response of individuals to tDOM concentrations}

The best models and the averaged model showed that survival probability of $C$. sphaericus significantly decreased along with size $\left(\beta_{1}\right)$ (Table 1, Fig. S3-S6 and Table S6 in Supplemental Material Appendix S4). Although the best three models (16-42\% of the weight) showed that higher concentrations of tDOM promoted the survivability of larger and older animals (Table S6 in Supplemental Material Appendix S4), the averaged model showed that tDOM neither considered as a separate variable $\left(\beta_{2}\right)$ nor in interaction with size and age $\left(\beta_{3}-\beta_{5}\right)$ had significant effect on survival of $C$. sphaericus (Table 1). Daily survival of $A$. harpae decreased with the size and age of this species $\left(\beta_{3}\right)$, whereas tDOM had a positive influence on its survivability $\left(\beta_{2}\right.$, Table 1 , Table S6 in Supplemental Material Appendix S4).

Daily growth was on average $1.23 \cdot 10^{-5} \mathrm{~mm}$ for $C$. sphaericus and $1.94 \cdot 10^{-5} \mathrm{~mm}$ for $A$. harpae and decreased with body size and age in both species (Fig. S7-S10 in Supplemental Material Appendix S4). The best models, describing the daily growth of $C$. sphaericus included body size $\left(\beta_{1}\right)$ and interaction between size and age $\left(\beta_{3}\right)$ as well as tDOM concentration in interaction with size as well as size and age $\left(\beta_{4}, \beta_{5}\right.$, Table S7 in Supplemental Material Appendix S4), however the averaged model showed the significance of $\beta_{1}$, $\beta_{3}$, and $\beta_{5}$ (Table 1). Thus, negative correlations between daily growth and body size in $C$. sphaericus were stronger in the group containing the oldest animals, and this effect was reinforced by tDOM concentration. For A. harpae, both the best models and the averaged model included the effects of body size $\left(\beta_{1}\right)$, as well as size:age interaction $\left(\beta_{3}\right)$, and these variables had a negative influence on daily growth rate (Table 1, Table S7 in Supplemental Material Appendix S4).

The averaged and best models describing the probability of carrying eggs for both $C$. sphaericus and A. harpae 

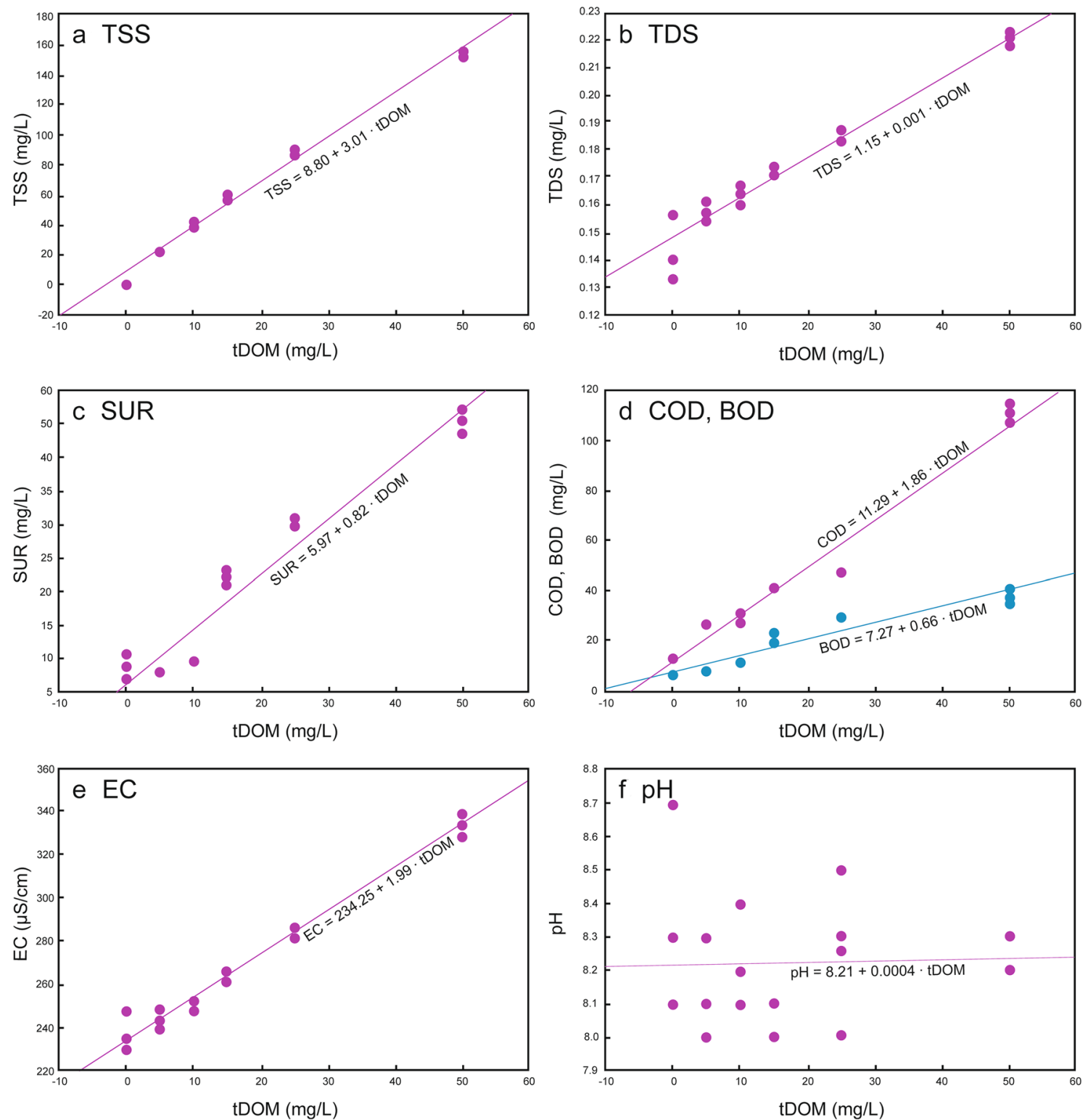

Fig. 1 Linear relationships between tDOM concentration and total suspended solids (TSS), total dissolved solids (TDS), and surfactant (SUR) concentrations, chemical and biochemical oxygen demands (COD, BOD), electric conductivity (EC), and pH in the experimental treatments

included body size $\left(\beta_{1}\right)$, tDOM concentration $\left(\beta_{2}\right)$, and tDOM:size interactions $\left(\beta_{4}\right.$, Table 1, Table S8 in Supplemental Material Appendix S4). The probability of carrying eggs in $C$. sphaericus decreased with size $\left(\beta_{1}\right)$, but increased with tDOM concentration $\left(\beta_{2}\right)$, such that larger individuals were less likely to be carrying eggs at higher tDOM concentrations ( $\beta_{4}$, Table 1, Fig. S11-S12 in Supplemental Material Appendix S4). For A. harpae, the opposite phenomenon was observed; the probability of this species carrying eggs increased with body size $\left(\beta_{1}\right)$ and decreased with $\mathrm{tDOM}$ concentration $\left(\beta_{2}\right)$, thus larger individuals living under higher tDOM concentrations displayed a higher probability of carrying eggs than their equivalents living under lower tDOM concentrations $\left(\beta_{4}\right.$, Table 1, Figs. S13-S14 in Supplemental Material Appendix S4).

Both C. sphaericus and A. harpae carried a maximum of two eggs (Figs. S15-S18 in Supplemental Material Appendix S4) and their brood size significantly increased with body size $\left(\beta_{1}\right.$, Table 1$)$. All the best models describing the brood size of $C$. sphaericus also included the effect of the interaction between tDOM concentration and size $\left(\beta_{4}\right)$, suggesting that the correlation between brood size and body size was enhanced by tDOM (Table S9 in Supplemental Material Appendix S4), and both $\beta_{1}$ and $\beta_{4}$ were significant in the averaged model describing brood size of $C$. sphaericus (Table 1). 
Table 1 Averaged coefficients and standard errors for each of the individual traits, daily survival probability $S$, daily growth $G$, probability of carrying eggs $p$, brood-size $f$, and neonate body size at birth $r$ as single and interacted effect of size distribution $x$, age structure $A$ and tDOM concentration $M$

\begin{tabular}{|c|c|c|c|c|c|c|}
\hline & & $S$ & $G$ & $p$ & $f$ & $r$ \\
\hline \multicolumn{7}{|c|}{ Chydorus } \\
\hline & $\beta_{0}$ & $2.13 \mathrm{e}+00[1.50 \mathrm{e}+00]$ & $4.20 \mathrm{e}-02[1.77 \mathrm{e}-03]$ & $5.09 \mathrm{e}+00[8.38 \mathrm{e}-01]$ & $-4.10 \mathrm{e}-01[4.54 \mathrm{e}-02]$ & $-2.75 e+00[6.77 e-02]$ \\
\hline$x$ & $\beta_{1}$ & $-5.54 e-02[9.51 e-03]$ & $-1.90 e+00[9.16 e-02]$ & $-2.09 e-02[5.53 e-03]$ & $4.12 \mathrm{e}-01[1.13 \mathrm{e}-01$ & $8.88 \mathrm{e}-02[5.02 \mathrm{e}-02]$ \\
\hline$M$ & $\beta_{2}$ & & $6.38 \mathrm{e}-02[4.04 \mathrm{e}-02]$ & $2.66 \mathrm{e}-02[9.23 \mathrm{e}-03]$ & $1.43 \mathrm{e}-02[4.42 \mathrm{e}-02]$ & $-1.29 \mathrm{e}-02[4.13 \mathrm{e}-02]$ \\
\hline$x A$ & $\beta_{3}$ & $1.53 \mathrm{e}-06[4.41 \mathrm{e}-06]$ & $-6.39 \mathrm{e}-01[2.63 \mathrm{e}-02]$ & $2.03 \mathrm{e}-07[5.21 \mathrm{e}-06]$ & $-4.41 \mathrm{e}-02[2.42 \mathrm{e}-02]$ & $9.22 \mathrm{e}-02[1.03 \mathrm{e}-01]$ \\
\hline$M x$ & $\beta_{4}$ & $1.01 \mathrm{e}-05[1.37 \mathrm{e}-05]$ & $1.34 \mathrm{e}-01[5.49 \mathrm{e}-02]$ & $-8.62 e-05[3.88 e-05]$ & $6.12 \mathrm{e}-02[5.69 \mathrm{e}-02]$ & $1.06 \mathrm{e}-01[7.47 \mathrm{e}-02]$ \\
\hline$M x A$ & $\beta_{5}$ & $6.76 \mathrm{e}-07[3.87 \mathrm{e}-07]$ & $-1.13 \mathrm{e}-01$ [3.32e-02] & $2.72 \mathrm{e}-07[2.66 \mathrm{e}-07]$ & $-3.35 \mathrm{e}-02[2.27 \mathrm{e}-02]$ & $-5.29 e-01[1.25 e-01]$ \\
\hline \multicolumn{7}{|c|}{ Acroperus } \\
\hline & $\beta_{0}$ & $-4.84 e+00[1.05 e+00]$ & $7.05 \mathrm{e}-02[1.59 \mathrm{e}-03]$ & $-5.02 e+00[5.77 e-01]$ & $2.50 \mathrm{e}-01[1.34 \mathrm{e}-01]$ & $-7.77 \mathrm{e}+00[7.42 \mathrm{e}-02]$ \\
\hline$x$ & $\beta_{1}$ & $-6.67 e-03[4.06 e-03]$ & $-1.61 e+00[6.22 e-02]$ & $1.27 \mathrm{e}-02[2.50 \mathrm{e}-03]$ & $3.89 \mathrm{e}-01[7.51 \mathrm{e}-02]$ & $7.06 \mathrm{e}-01[2.92 \mathrm{e}-01]$ \\
\hline$M$ & $\beta_{2}$ & $1.68 \mathrm{e}-02[6.65 \mathrm{e}-03]$ & $-7.30 \mathrm{e}-03$ [5.11e-03] & $-1.19 \mathrm{e}-01[2.57 \mathrm{e}-02]$ & $-1.01 \mathrm{e}-01$ [3.36e-02] & $8.10 \mathrm{e}-02[7.87 \mathrm{e}-02]$ \\
\hline$x A$ & $\beta_{3}$ & $-2.11 e-05[9.88 e-06]$ & $-6.19 e-01[2.46 e-02]$ & $5.19 \mathrm{e}-07[5.26 \mathrm{e}-06]$ & $-1.61 \mathrm{e}-02[1.43 \mathrm{e}-02]$ & $-3.76 e-01[1.43 e-01]$ \\
\hline$M x$ & $\beta_{4}$ & $1.32 \mathrm{e}-05[1.29 \mathrm{e}-05]$ & $-7.77 \mathrm{e}-03[6.90 \mathrm{e}-03]$ & $2.61 e-04[8.01 e-05]$ & $4.51 \mathrm{e}-02[3.19 \mathrm{e}-02]$ & $-1.62 \mathrm{e}-02[9.38 \mathrm{e}-02]$ \\
\hline$M x A$ & $\beta_{5}$ & $-3.35 \mathrm{e}-07[2.74 \mathrm{e}-07]$ & $-1.53 \mathrm{e}-02[1.09 \mathrm{e}-02]$ & $-1.46 \mathrm{e}-06[8.12 \mathrm{e}-07]$ & $-4.02 \mathrm{e}-05[1.53 \mathrm{e}-02]$ & $-1.07 \mathrm{e}-01[7.84 \mathrm{e}-02]$ \\
\hline
\end{tabular}

Bold numbers indicate significant effects $(p<0.05)$

The following regression was used for each trait (but with different link function; see main text): $y(x, x A, M)=\beta_{0}+\beta_{1} x+\beta_{2} M+\beta_{3} x: A+\beta_{4}$ $M: x+\beta_{5} M: x: A+\varepsilon_{\text {res }}$

The best models and the averaged model describing brood size of $A$. harpae indicated a significant influence of body size $\left(\beta_{1}\right)$ and $\mathrm{tDOM}$ concentration $\left(\beta_{2}\right)$, suggesting that while larger individuals carried bigger broods, tDOM concentration had a significant negative effect on $A$. harpae brood size (Table 1, Table S9 in Supplemental Material Appendix S4).

Neonate size was negatively correlated with tDOM concentration for $C$. sphaericus $\left(\beta_{2}\right.$, Figs. S19-S20 in Supplemental Material Appendix S4) and this negative effect was significantly higher for larger and older maternal individuals $\left(\beta_{5}\right.$, Table 1$)$. The effects of the interaction between tDOM, body size, and age of mothers $\left(\beta_{5}\right)$ was significant in all the best models describing neonate body size for $C$. sphaericus (Table S10 in Supplemental Material Appendix S4). However, tDOM concentration had no effect on neonate size of $A$. harpae (Fig. S21-S22 in Supplemental Material Appendix S4). Larger individuals of this species produced bigger neonates $\left(\beta_{1}\right)$, but this trend was reduced in the group of the oldest animals $\left(\beta_{3}\right.$, Table 1$)$. The influence of $\beta_{1}$ was significant in both the averaged and best models (Table 1, Table S10 in Supplemental Material Appendix S4).

\section{Response at population and community level to tDOM concentrations}

Although populations of $C$. sphaericus significantly increased throughout experiment, tDOM concentration had no apparent effect on the changes population size of $C$. sphaericus, since similar increases in population size were observed in all the treatments throughout the experiment (Table 2, Fig. 2a, Fig. S23 in Supplemental Material Appendix S5). A. harpae populations, however, displayed significant differences in size throughout experiment associated with tDOM concentration levels (Table 2). In environments with tDOM concentrations of $0-10 \mathrm{mg} / \mathrm{L}$, a steady increase in population size was observed, under tDOM concentrations of $15-25 \mathrm{mg} / \mathrm{L}$ populations displayed a weak increase, whereas with $50 \mathrm{mg} / \mathrm{L}$ of tDOM, population density oscillated around the initial number of individuals and, after 44 days of the experiment, a steady decrease in population size was observed (Fig. 2b, Fig. S24 in Supplemental Material Appendix S5).

Similar patterns were found in asexual reproduction. $F_{\text {asex }}$ of $C$. sphaericus ranged between 5.2 and $6.3 \%$ and was affected by neither tDOM concentration nor time of the experiment (Table 2). Despite insignificant differences, however, large fluctuations in $F_{\text {asex }}$ were observed in each treatment throughout the experiment, and the ranges of these fluctuations increased with tDOM concentration (Fig. 3a, Fig. S25 in Supplemental Material Appendix S5). $F_{\text {asex }}$ in $A$. harpae, conversely, differed significantly among treatments (Table 2). With tDOM concentrations of $0-10 \mathrm{mg} / \mathrm{L}, F_{\text {asex }}$ ranged between $5.7 \%$ and $6.4 \%$, but with tDOM concentrations of $15 \mathrm{mg} / \mathrm{L}, F_{\text {asex }}$ values achieved $4.7-6 \%$ during the first 16 days of the experiment and then decreased to $1.3-2.3 \%$ during the remainder of the experiment. Low values of $F_{\text {asex }}(1.1-1.4 \%)$ in $A$. harpae populations were also observed in treatments with tDOM concentrations of $25-50 \mathrm{mg} / \mathrm{L}$ (Fig. 3b, Fig. S26 in Supplemental Material Appendix S5). 
Table 2 The results of repeated measures ANOVA showing differences in population responses to tDOM concentration throughout the experiment

\begin{tabular}{|c|c|c|c|c|}
\hline & SS & df & MS & $\mathrm{F}$ \\
\hline \multicolumn{5}{|l|}{ Population size } \\
\hline \multicolumn{5}{|l|}{ C. sphaericus } \\
\hline $\mathrm{tDOM}$ & 4379 & 5 & 876 & 0.169 \\
\hline Error & 62,192 & 12 & 5183 & \\
\hline Time & 469,120 & 24 & 19,547 & 105.909 \\
\hline $\mathrm{tDOM} \times$ time & 17,595 & 120 & 147 & 0.794 \\
\hline Error & 53,154 & 288 & 185 & \\
\hline \multicolumn{5}{|l|}{ A. harpae } \\
\hline $\mathrm{tDOM}$ & $75,145.9$ & 5 & $15,029.2$ & 19.297 \\
\hline Error & 9346.2 & 12 & 778.9 & \\
\hline Time & $41,531.2$ & 24 & 1730.5 & 46.01 \\
\hline tDOM $\times$ time & $38,550.5$ & 120 & 321.3 & 85,416 \\
\hline Error & $10,831.8$ & 288 & 37.6 & \\
\hline \multicolumn{5}{|l|}{$F_{\text {asex }}$} \\
\hline \multicolumn{5}{|l|}{ C. sphaericus } \\
\hline $\mathrm{tDOM}$ & 51.78 & 5 & 10.36 & 0.568 \\
\hline Error & 218.96 & 12 & 18.25 & \\
\hline Time & 130.59 & 24 & 5.44 & 0.912 \\
\hline $\mathrm{tDOM} \times$ time & 714.56 & 120 & 5.95 & 0.998 \\
\hline Error & 1718.37 & 288 & 5.97 & \\
\hline \multicolumn{5}{|l|}{ A. harpae } \\
\hline $\mathrm{tDOM}$ & 2364.951 & 5 & 472.9 & 62.935 \\
\hline Error & 90.187 & 12 & 7.516 & \\
\hline Time & 29.476 & 24 & 1.228 & 0.319 \\
\hline tDOM $\times$ time & 402.604 & 120 & 3.355 & 0.87 \\
\hline Error & 1110.48 & 288 & 3.856 & \\
\hline \multicolumn{5}{|l|}{$F_{\text {sex }}$} \\
\hline \multicolumn{5}{|l|}{ C. sphaericus } \\
\hline $\mathrm{tDOM}$ & 11.824 & 5 & 2.365 & 9.212 \\
\hline Error & 3.08 & 12 & 0.257 & \\
\hline Time & 4.032 & 24 & 0.168 & 0.778 \\
\hline $\mathrm{tDOM} \times$ time & 24.355 & 120 & 0.203 & 0.941 \\
\hline Error & 62.139 & 288 & 0.216 & \\
\hline \multicolumn{5}{|l|}{ A. harpae } \\
\hline $\mathrm{tDOM}$ & 1444.012 & 5 & 288.802 & 201.897 \\
\hline Error & 17.165 & 12 & 1.430 & \\
\hline Time & 88.478 & 24 & 3.687 & 2.521 \\
\hline $\mathrm{tDOM} \times$ time & 207.022 & 120 & 1.725 & 1.180 \\
\hline Error & 421.128 & 288 & 1.462 & \\
\hline
\end{tabular}

Significant differences $(p<0.05)$ are in bold

For both species, significant differences in sexual reproduction in relation to concentrations of $\mathrm{tDOM}$ were observed (Table 2). In the case of $C$. sphaericus, $F_{\text {sex }}$ was significantly higher in tDOM concentrations $\geq 15 \mathrm{mg} / \mathrm{L}(0.6 \%-0.8 \%$ vs $0.3 \%-0.5 \%$ at $\leq 10 \mathrm{mg}$ tDOM/L, Fig. 4a, Fig. S27 in Supplemental Material Appendix S5). $F_{\text {sex }}$ of $A$. harpae ranged between 0.1 and $0.2 \%$ in environments with tDOM concentrations of $0-5 \mathrm{mg} / \mathrm{L}$, and between 2 and $5 \%$ in environments with $10-50 \mathrm{mg} / \mathrm{L}$ of tDOM. Moreover, experimental populations differed significantly in $F_{\text {sex }}$ values throughout experiment (Table 2, Fig. 4b, Fig. S28 in Supplemental Material Appendix S5).

The resilience of invertebrate communities $(R)$ ranged on average between $R=-0.24$ and $R=-0.70$, and differences in $R$ values were insignificant at all tDOM concentrations (ANOVA, $F_{4,10}=0.514, p>0.01$, Fig. 5a). In comparison to the communities, the $R \mathrm{~s}$ of species' populations differed significantly across tDOM concentrations. The resilience of the A. harpae population in the treatment with $5 \mathrm{mg} / \mathrm{L}$ of tDOM was significantly higher than the resilience of the other A. harpae populations (ANOVA, $F_{4,10}=15,160$, $p<0.01$; Tukey HSD, $p<0.01$, Fig. 5a). Populations of $C$. sphaericus, on the other hand, demonstrated significantly higher $R \mathrm{~s}$ in treatments with $\mathrm{tDOM}$ concentration $\geq 25 \mathrm{mg} / \mathrm{L}$ (ANOVA, $F_{4,10}=11.248, p<0.05$; Tukey HSD, $p<0.05$, Fig. 5a). The resilience of the invertebrate communities showed significant correlation with $C$. sphaericus populations (Spearman's rank correlation, $r=0.43, p_{a d j}<0.05$, Fig. S29 in Supplemental Material Appendix S6) and did not correlate significantly with the resilience of $A$. harpae populations (Spearman's rank correlation, $r=0.21, p_{a d j}>0.05$, Fig. S30 in Supplemental Material Appendix S6). The temporal stability $(D)$ of the invertebrate communities significantly correlated with the temporal stabilities of $C$. sphaericus populations (Spearman's rank correlation, $\mathrm{r}=0.62, p_{a d j}<0.05$, Fig. S31 in Supplemental Material Appendix S6). Both invertebrate communities and C. sphaericus populations showed high temporal stability across tDOM concentrations, since mean values of $D$ ranged between 1.56 and 1.92 for communities and between 1.36 and 1.70 for $C$. sphaericus, and differences between values of $D$ s were insignificant across treatments (ANOVA, $F_{4,10}=0.589, p>0.05$ for the communities; $F_{4,10}=0.553, p>0.05$ for $C$. sphaericus, Fig. 5b). The mean values of temporal stability of $A$. harpae populations, however, showed a significant decrease along with increasing tDOM concentrations $(D=0.40-1.79$; ANOVA, $F_{4,10}=17.508, p<0.01$; Tukey HSD, $p<0.05$, Fig. 5b) and was uncorrelated with the $\mathrm{D}$ of the communities (Spearman's rank correlation, $r=0.07, p_{a d j}>0.05$, Fig. S32 in Supplemental Material Appendix S6). The relationships between the two aspects of functional stability produced an insignificant correlation for the C. sphaericus (Spearman's rank correlation, $r=0.03, p_{a d j}<0.05$, Fig. S33 in Supplemental Material Appendix S6) and a significant positive correlation for A. harpae (Spearman's rank correlation, $r=0.77$, $p_{\text {adj }}>0.05$, Fig. S34 in Supplemental Material Appendix S6) and invertebrate communities (Spearman's rank correlation, $r=0.65, p_{a d j}>0.05$, Fig. S35 in Supplemental Material Appendix S6). 
Fig. 2 Population sizes of $C$. sphaericus (a) and A. harpae (b) under different tDOM concentrations
Fig. 3 Asexual reproduction of C. sphaericus (a) and A. harpae (b) under different tDOM concentrations. Reproductive effort is expressed as the percentage quotient of the number of embryo-bearing parthenogenetic females to total number of individuals
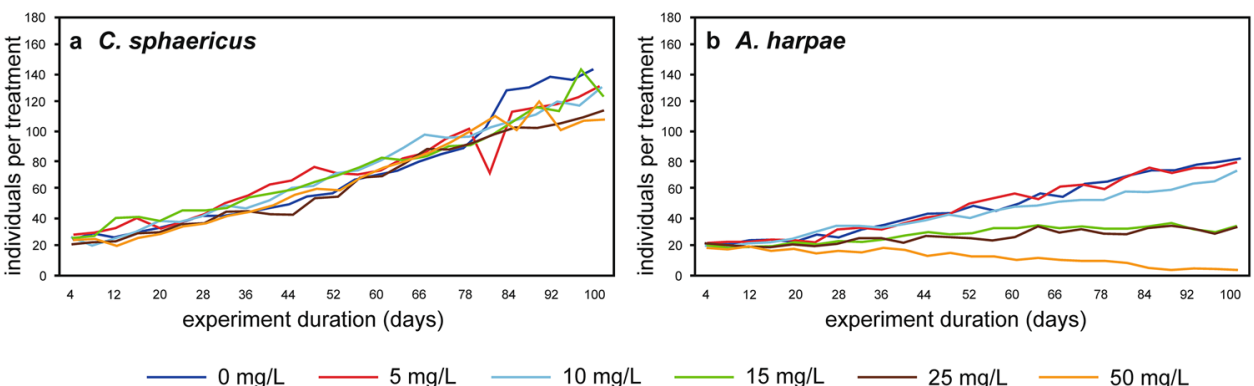

$-0 \mathrm{mg} / \mathrm{L} \longrightarrow 5 \mathrm{mg} / \mathrm{L}=10 \mathrm{mg} / \mathrm{L}$

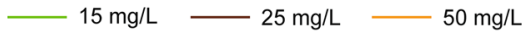

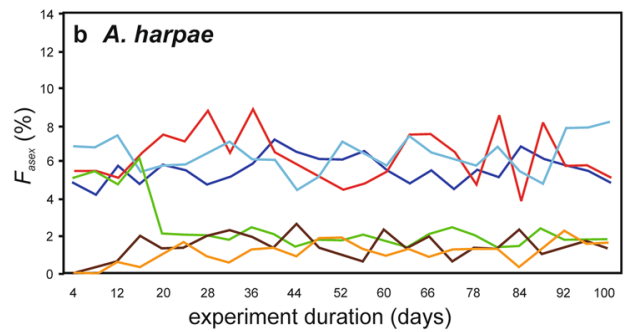

$15 \mathrm{mg} / \mathrm{L}$

$-25 \mathrm{mg} / \mathrm{L}$

$55 \mathrm{mg} / \mathrm{L}$
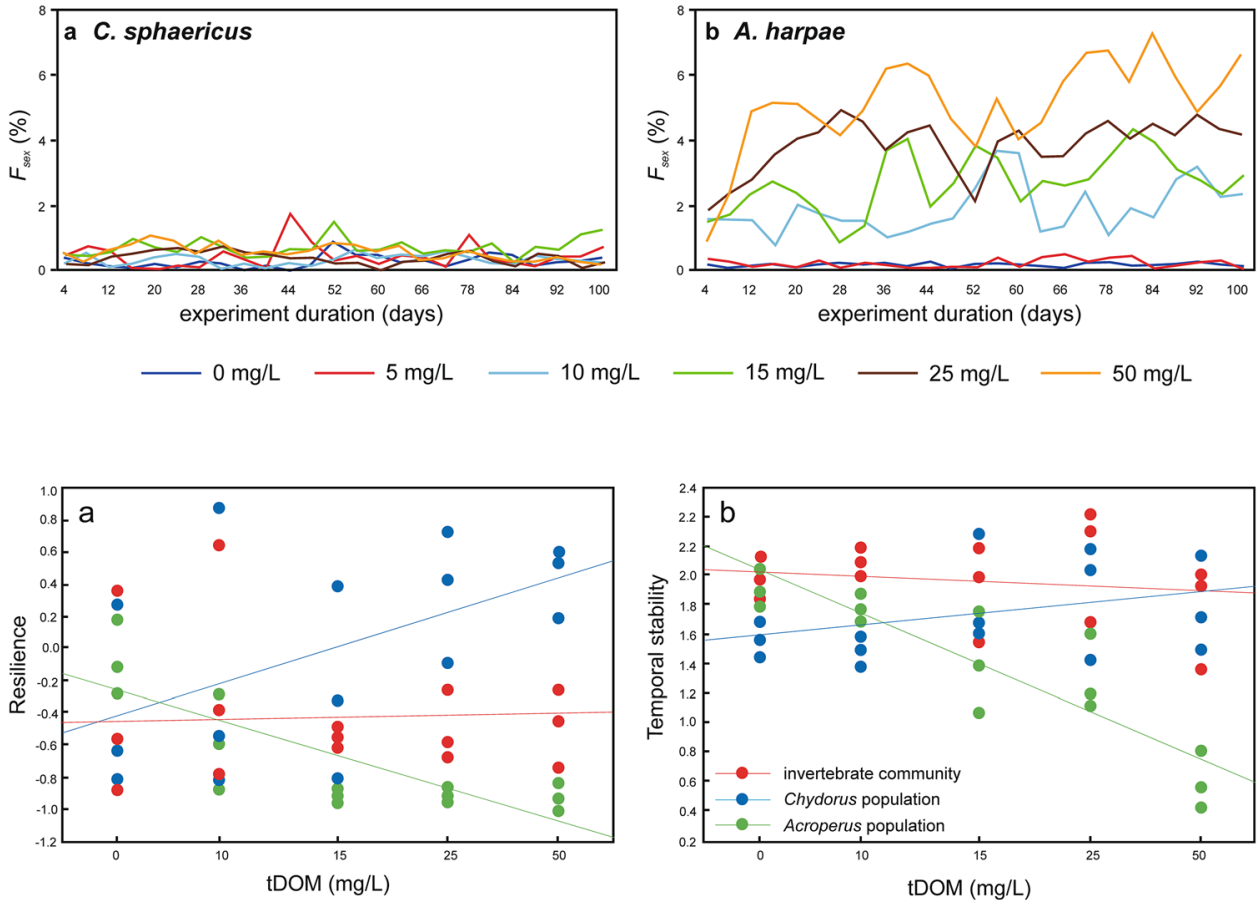

Fig. 5 The functional stability, expressed as resilience (a) and temporal stability (b), of $C$. sphaericus and $A$. harpae populations as well as invertebrate communities across tDOM concentrations
Fig. 4 Sexual reproduction of concentrations. Reproductive effort is expressed as percentage quotient of ephippial females to total number of individuals

\section{Discussion}

Increased amount of organic matter in browning freshwaters correlates with a decrease in the biomass of edible phytoplankton and oxygen depletion (Carpenter et al. 1998), and through decreased concentration of oxygen and biomass of phytoplankton it influences species structure and abundance of invertebrates (Brothers et al. 2014). In this experiment, invertebrates were systematically fed on algae, and oxygen availability was passively replenished from the air. Thus, the any alterations in observed traits were the result of above mechanism of tDOM influence on experimental populations. Terrestrial organic matter is a mixture of organic compounds (Vitale and Di Guardio 2020) and the addition of tDOM significantly altered 
the chemical characteristics of treatments in this experiment. Values of TSS, TDS, SUR, and EC that increased with $\mathrm{tDOM}$ concentration showed that $\mathrm{tDOM}$ was a rich source of colloidal and ionic salts. The responses of $C$. sphaericus and $A$. harpae individuals to the above alterations were reflected in the daily changes in their individual traits. These rates combined in the IPM model revealed a set of differences between the two species. In this model, body size was used as a continuous state variable in discrete time. Cladocerans grow in length throughout their life (Lynch 1980), thus the body size of individuals is often used to estimate their relative age. Daily observations of $C$. sphaericus and A. harpae from their birth to death allowed to estimate their actual age in this experiment. The application of size and size-age relationships as independent variables in the IPM allowed to discriminate between changes in individual traits that resulted from the size and age of individuals from those that were caused by tDOM concentration. The results of the IPM model indicated that individual traits altered along with body size of C. sphaericus, whereas alterations in individual traits of $A$. harpae were connected mainly with age. This observation may suggest that $C$. sphaericus are more able to respond flexibly to environmental change, since interplays between body size and individual traits (especially these resulting from fecundity) are important indicators of plasticity of life histories (Stearns 1989) that directly translate to population size. Moreover, the implementation of combinations of tDOM, size, and age $\left(\beta_{4}, \beta_{5}\right)$ as equivalent variables revealed lifetime changes in response to tDOM. C. sphaericus showed stronger responses to tDOM than $A$. harpae in terms of size $\left(\beta_{4}\right)$ and age $\left(\beta_{5}\right)$. This may suggest more efficient energy allocation during the lifetime of $C$. sphaericus in order to reduce tDOM effects. The higher flexibility in response to tDOM demonstrated by C. sphaericus was also seen in growth rate. Body growth of both species was negatively correlated with body size and age $\left(\beta_{1}, \beta_{3}\right)$, which means that the growth dynamic was slower in larger and older individuals, however in the case of $C$. sphaericus this negative correlation was significantly stronger at higher concentration of tDOM. Many studies have revealed trade-offs between growth, survivability, and reproduction (Roff 2002). These trade-offs among individual traits were clearer for $C$. sphaericus. Decreased growth in larger and older individuals associated with tDOM concentration $\left(\beta_{5}\right)$ correlated with decreased probability of carrying eggs and increased brood size. Trade-offs among individual traits of $A$. harpae displayed the opposite pattern. Increasing concentrations of tDOM $\left(\beta_{2}\right)$ correlated with increased survival probability and decreased probability of carrying eggs and smaller brood size. Life histories of cladocerans often show trade-off between brood size and neonate size; this trade-off is most often observed in food-limited environments where food availability correlates positively with brood size and negatively with neonate size (Guinnee et al. 2004). In this experiment, the neonate size of $C$. sphaericus was negatively affected by tDOM concentration $\left(\beta_{2}\right)$ and showed negative correlation with the probability of carrying eggs. This trade-off is in accordance with some observations that females produce smaller offspring when their reproductive value in the next time step is large relative to current reproductive prospects (Kindsvater and Otto 2014). tDOM concentration had no influence on neonate size of $A$. harpae, which was affected exclusively by the size and age of individuals $\left(\beta_{1}\right.$, $\beta_{3}$ ), similarly to the survival probability of $C$. sphaericus. These findings might suggest some individual traits are neutral, developing regardless of the impact of stressful factors. It is also apparent that neither species performed maximally across all the individual traits in response to increased tDOM concentrations.

The individual traits of both species were reflected in their population traits. Although species may respond differently to allochthonous inputs (Adamczuk et al. 2019) there are some reports that moderate concentrations of organic carbon may correlate positively with the abundance of planktonic animals (e.g. Kelly et al. 2016). A similar phenomenon was observed in this experiment, since both the species developed well under tDOM concentration $\leq 10 \mathrm{mg} / \mathrm{L}$, and the populations of $C$. sphaericus also increased in size under higher concentrations of tDOM. For $C$. sphaericus the consequences of increased tDOM observed at population level were higher fluctuations in $F_{\text {asex }}$ and increased $F_{\text {sex }}$, but these changes appeared to have no influence on population size. Populations of A. harpae responded more strongly to tDOM. Populations of this species in treatments with tDOM concentrations of $\geq 15 \mathrm{mg} / \mathrm{L}$ showed decreases in abundance as well as a decrease in asexual reproduction in favour of sexual reproduction. Both species, similarly to other cladocerans, are facultative sexual organisms (Gilbert and Williamson 1983; Nevalainen et al. 2011b) although asexual reproduction is dominant and enables the species to expand a population more rapidly. Sexual reproduction provides a temporary escape from unfavourable conditions through diapause, and an increase in population fitness due to the greater genetic variability of the following generation (Hurst and Peck 1996). However, populations that trigger sexual reproduction bear costs comprising the production of males, melanisation of the ephippia, and dormancy of ephippial eggs. Thus, although a strategy of sexual reproduction allows cladocerans to survive harsh conditions, it may reduce the growth rate of the population. The decreases observed in the A. harpae population size could be an effect of reduced asexual reproduction in favour of sexual reproduction that did not provide an equivalent number of offspring to sustain the population. Trade-offs among the 
individual traits of $C$. sphaericus that resulted in population growth are in the accordance of assumptions of life-history hypothesis (McNamara and Houston 1996), whereas the strategy adopted by A. harpae, observed at individual level, was clear only in the context of the population dynamics of this species. At population level, A. harpae constrained asexual reproduction and invested in sexually reproducing individuals to escape from unfavourable conditions temporarily through diapausing eggs. Contemporaneously, at individual level, organisms prolonged survivability at the cost of reproduction. Diminishing reproduction to save energy for the physiological processes involved in neutralizing the effects of physiological stress is a strategy that has been observed in organisms exposed to detrimental factors (Tuljapurkar 1990). Thus, a decline in asexual reproduction might be considered to be the direct effect of a harmful influence, but investment in sexual reproduction at population level, as well as low parthenogenetic reproduction and high survivability at individual level, may, in combination, be a direct mitigating choice for $A$. harpae to overcome adverse conditions.

Alterations in individual traits and promotion of either asexual or sexual reproduction had consequences reflected in functional stability, expressed as the resilience and temporal stability of populations. Both aspects of functional stability decreased along with increased concentrations of tDOM in the A. harpae populations, whereas in the $C$. sphaericus populations the contrary trend was observed. Interestingly, the resilience and temporal stability of $C$. sphaericus were highest in those environments with tDOM concentrations $\geq 25 \mathrm{mg} / \mathrm{L}$, which may suggest that $C$. sphaericus prefers higher tDOM concentrations. However, in regard to the observed alterations in individuals' traits, the high resilience of $C$. sphaericus reared in treatments with high concentration of tDOM results from overcompensation stemming from high offspring production at the cost of individual body growth. In the case of A. harpae populations, the decreased resilience and temporal stability associated with increased tDOM concentrations were the result of a mitigating strategy consisting of investing in resting eggs at the cost of the development of the existing population. The impact of environmental variables is usually considered in regard to the response of entire aquatic communities. Such an approach is as appropriate as communities show more stable development over time despite changes in species composition (Cottingham et al. 2001). In such communities the effect of species loss does not decrease the potential to drive ecosystem service delivery (Winfree et al. 2015). This experiment showed that even in a two-species community a decrease in abundance of one component could be compensated by the abundance of the other; thus, any decrease in abundance would not be observed at community level. The resilience $(R)$ and temporal stability $(D)$ of the community showed a strong positive correlation with the $R$ and $D$ of the $C$. sphaericus population, whereas the A. harpae population did not have a significant influence on the functional stability of the entire community. This is in agreement with other studies showing that dominant species make the major contribution to community stability (Dangles and Malmqvist 2004). However, although community stability was shaped by $C$. sphaericus, the relationships between the two aspects of the community functional stability were similar to these observed for $A$. harpae population, showing a significant positive correlation between resilience and temporal stability; such a correlation suggests there is a one-dimensional response to the environment. The resilience and temporal stability of the $C$. sphaericus population were, on the other hand, uncorrelated, suggesting non-dimensionality in functional stability. Moreover, both the populations showed significant differences in functional stability, whereas the functional stability of the community did not differ significantly among tDOM concentrations. This is evidence that invertebrate communities might be able to maintain their function in ecosystem service delivery in browning freshwaters due to species compensation. Thus, the effects of browning might be missed at community level.

\section{Conclusions}

Many freshwater systems have experienced a gradual, long-term increase in dissolved organic matter concentrations in recent decades, and the consequences of this phenomenon for the diversity and functioning of invertebrates remain poorly understood and hotly debated. The present study shows that observation of the reactions of invertebrates at several levels of organisation gives a more complete assessment of the risk of browning freshwater ecosystems. Moreover, the results of this study suggest that conclusions drawn from research on populations or communities omitting individual life histories might be misinterpreted. Thus, the linking of alterations at individual level with population and community responses to concentrations of dissolved organic matter is the ultimate target to adequately predict the response of aquatic communities to the browning of freshwater.

Supplementary Information The online version contains supplementary material available at https://doi.org/10.1007/s00027-021-00787-7.

Acknowledgements I would like to thank the two anonymous reviewers for their constructive criticism which helped greatly improve the previous draft of the paper. 


\section{Compliance with ethical standards}

Conflict of interests The author declares no competing interest.

Open Access This article is licensed under a Creative Commons Attribution 4.0 International License, which permits use, sharing, adaptation, distribution and reproduction in any medium or format, as long as you give appropriate credit to the original author(s) and the source, provide a link to the Creative Commons licence, and indicate if changes were made. The images or other third party material in this article are included in the article's Creative Commons licence, unless indicated otherwise in a credit line to the material. If material is not included in the article's Creative Commons licence and your intended use is not permitted by statutory regulation or exceeds the permitted use, you will need to obtain permission directly from the copyright holder. To view a copy of this licence, visit http://creativecommons.org/licenses/by/4.0/.

\section{References}

Adamczuk M, Mieczan T (2015) Different levels of precision in studies on the alimentary tract content of omnivorous fish affect predictions of their food niche and competitive interactions. CR Biol 338:678-687. https://doi.org/10.1016/j.crvi.2015.05.003

Adamczuk M, Ferencz B, Mieczan T, Dawidek J (2019) Allochthonous subsidies as driving forces for development of plankton in an autotrophic, temperate, and small lake. Hydrobiologia 846:59-73. https://doi.org/10.1007/s10750-019-04052-9

Battin TJ, Luyssaert S, Kaplan LA, Aufdenkampe AK, Richter A, Tranvik LJ (2009) The boundless carbon cycle. Nat Geosci 2:598-600. https://doi.org/10.1038/ngeo618

Belayeva M, Taylor DJ (2009) Cryptic species within the Chydorus sphaericus species complex (Crustacea: Cladocera) revealed by molecular markers and sexual stage morphology. MolPhylogenetEvol 50:534-546. https://doi.org/10.1016/j.ympev.2008.11.007

Bos DG, Cumming BF (2003) Sedimentary Cladoceran remains and their relationship to nutrients and other limnological variables in 53 lakes from British Columbia, Canada. Can J Fish AquatSci 60:1177-1189. https://doi.org/10.1139/f03-097

Brothers S, Köhler J, Attermeyer K, Grossart HP, Mehner T, Meyer N, Scharnweber K, Hilt S (2014) A feedback loop links brownification and anoxia in a temperate, shallow lake. LimnolOceanogr 59:1388-1398. https://doi.org/10.4319/lo.2014.59.4.1388

Brucet S, Boix D, Gascon S, Sala J, Quintana XD, Badosa A, Sondergaard M, Lauridsen TL, Jeppesen E (2009) Species richness of crustacean zooplankton and trophic structure of brackish lagoons in contrasting climate zones: north temperate Denmark and Mediterranean Catalonia (Spain). Ecography 32:692-702. https://doi. org/10.1111/j.1600-0587.2009.05823.x

Carpenter SR, Cole JJ, Kitchell JF, Pace ML (1998) Impact of dissolved organic carbon, phosphorus, and grazing on phytoplankton biomass and production in experimental lakes. LimnolOceanogr 43:73-80. https://doi.org/10.4319/lo.1998.43.1.0073

Cottingham KL, Brown BL, Lennon JT (2001) Biodiversity may regulate the temporal variability of ecological systems. EcolLett 4:72-85. https://doi.org/10.1046/j.1461-0248.2001.00189.x

Dadi T, Friese K, Wendt-Potthoff K, Koschorreck M (2015) Benthic dissolved organic carbon fluxes in a drinking water reservoir. LimnolOceanogr 61:445-459. https://doi.org/10.1002/lno.10224

Dakos V, Carpenter SR, Brock WA, Ellison AM, Guttal V, Ives AR, Kéfi S, Livina V, Seekell DA, van Nes EH, Scheffer M (2012) Methods for detecting early warnings of critical transitions in time series illustrated using simulated ecological data. PlosOne 7:e41010. https://doi.org/10.1371/journal.pone.0041010
Dangles O, Malmqvist B (2004) Species richness-decomposition relationships depend on species dominance. EcolLett 7:395-402. https://doi.org/10.1111/j.1461-0248.2004.00591.x

Desmarais KH (1997) Keeping Daphnia out of the surface film with cetyl alcohol. J Plankton Res 19:149-154. https://doi.org/10.1093/ plankt/19.1.149

Easterling MR, Ellner SP, Dixon PM (2000) Size-specific sensitivity: applying a new structured population model. Ecology 81:694708. https://doi.org/10.1890/0012-9658(2000)081[0694:SSSAA $\mathrm{N}] 2.0 . \mathrm{CO} ; 2$

Fortino K, Whalen SC, Johnson CR (2014) Relationships between lake transparency, thermocline depth, and sediment oxygen demand in Arctic lakes. Inland Waters 4:79-90. https://doi.org/10.5268/ IW-4.1.597

Galapate RP, Baes AU, Okada M (2001) Transformation of dissolved organic matter during ozonation: effects on trihalomethane formation potential. Water Res 35:2201-2206. https://doi.org/10.1016/ S0043-1354(00)00489-9

Gilbert JJ, Williamson CE (1983) Sexual dimorphism in zooplankton (Copepoda, Cladocera, Rotifera). Annu Rev Ecol Syst 14:1-33. https://doi.org/10.1146/annurev.es.14.110183.000245

Grueber CE, Nakagawa S, Laws RJ, Jamieson IG (2011) Multimodel inference in ecology and evolution: challenges and solutions. J Evolution Biol 24:699-711. https://doi.org/10.111 1/j.1420-9101.2010.02210.x

Guinnee MA, West SA, Little TJ (2004) Testing small clutch size models with Daphnia. The AmeNatt 163:880-887

Höss S, Jüttner I, Traunspurger W, Pfister G, Schramm KW, Steinberg CEW (2002) Enhanced growth and reproduction of Caenorhabditis elegans (Nematoda) in the presence of 4-nonylphenol. Environ Pollut 120:169-172. https://doi.org/10.1016/S0269 $-7491(02) 00161-6$

Hurst LD, Peck JR (1996) Recent advances in understanding of the evolution and maintenance of sex. Trends EcolEvol 11:46-52. https://doi.org/10.1016/0169-5347(96)81041-X

Jansson M, Persson L, De Roos AM, Jones RI, Tranvi LJ (2007) Terrestrial carbon and intraspecific size-variation shape lake ecosystems. Trends EcolEvol 22:316-322. https://doi.org/10.1016/j. tree.2007.02.015

Jones RI (1992) The influence of humic substances on lacustrine planktonic food chains. Hydrobiologia 229:73-91. https://doi. org/10.1007/BF00006992

Karlsson J, Byström P, Ask J, Persson L, Jansson M (2009) Light limitation of nutrient-poor lake ecosystems. Nature 460:506-509. https://doi.org/10.1038/nature08179

Kelly PT, Craig N, Solomon CT, Weidel BC, Zwart JA, Jones SE (2016) Experimental whole-lake increase of dissolved organic carbon concentration produces unexpected increase in crustacean zooplankton density. Glob Change Biol 22:2766-2775. https://doi. org/10.1111/gcb. 13260

Kilham SS, Kreeger DA, Goulden LSG, CE, Herrera L, (1998) COMBO: a defined freshwater culture medium for algae and zooplankton. Hydrobiologia 377:147-159. https://doi. org/10.1023/A:1003231628456

Kindsvater HK, Otto SP (2014) The evolution of offspring size across life-history stages. Am Nat 184:543-555. https://doi. org/10.1086/678248

Larsen S, Andersen T, Hessen DO (2011) Climate change predicted to cause severe increase of organic carbon in lakes. Glob Change Biol 17:1186-1192. https://doi.org/10.1111/j.1365-2486.2010.02257.x

Leenheer JA, Croué JP (2003) Characterizing aquatic dissolved organic matter. Environ SciTechnol 37:18-26

Lindell MJ, Granéli HW, Bertilsson S (2000) Seasonal photoreactivity of dissolved organic matter from lakes with contrasting humic content. Can J Fish AquatSci 57:875-885. https://doi.org/10.1139/ f00-016 
Lutz I, Zhang J, Opitz R, Kloas W, Xu Y, Menzel R, Steinberg CEW (2005) Environmental signals: synthetic humic substances act as xeno-estrogen and affect the thyroid system of Xenopus laevis. Chemosphere 61:1183-1188. https://doi.org/10.1016/j.chemo sphere.2005.02.073

Lynch M (1980) The evolution of cladoceran life histories. Q Rev Biol 55:23-42. https://doi.org/10.1086/411614

McNamara JM, Houston AI (1996) State-dependent life histories. Nature 380:215-221. https://doi.org/10.1038/380215a0

Meems N, Steinberg CEW, Wiegand C (2004) Direct and interacting toxicological effects on the waterflea (Daphnia magna) by natural organic matter, synthetic humic substances and cypermethrin. Sci Total Environ 319:123-136. https://doi.org/10.1016/S0048 $-9697(03) 00445-5$

Meyer-Jacob C, Tolu J, Bigler C, Yang H, Bindler R (2015) Early land use and centennial scale changes in lake-water organic carbon prior to contemporary monitoring. PNAS 112:6579-6584. https ://doi.org/10.1073/pnas.1501505112

Minguez L, Sperfeld E, Berer SA, Nejstgaard JC, Gessner MO (2020) Changes in food characteristics reveal indirect effects of lake browning on zooplankton performance. LimnolOceanogr 65:1028-1040. https://doi.org/10.1002/lno.11367

Mortimer CH (1942) The exchange of dissolved substances between mud and water in lakes. J Ecol 30:147-201. https://doi. org/10.2307/2256395

Nevalainen L, Luoto TP, Levine S, Manca M (2011a) Modern and pre-Industrial age distributions of Cladocera in Italian and Swiss Alpine lakes. Hydrobiologia 676:173-185. https://doi. org/10.1007/s10750-011-0802-5

Nevalainen L, Luoto TP, Levine S, Manca M (2011b) Paleolimnological evidence for increased sexual reproduction in chydorids (Chydoridae, Cladocera) under environmental stress. J Limnol 70:255-262. https://doi.org/10.3274/JL11-70-2-08

Nova CC, Bozelli RL, Spitzy A, Müller-Navarra D (2019) Living in a browning environment: effects on Daphnia`s growth and fatty acid pattern. LimnolOceanogr 64:18-31. https://doi.org/10.1002/ lno. 11016

Raftery AE, Madigan D, Hoeting JA (1997) Bayesian model averaging for linear regression models. J Am Stat Assoc 92:179-191. https ://doi.org/10.1080/01621459.1997.10473615

Roff DA (2002) Life History Evolution. Sinauer Associates, Sunderland

Roulet N, Moore TR (2006) Browning the waters. Nature 444:283-284. https://doi.org/10.1038/444283a
Smirnov NN (1996) The Chydorinae and Sayciinae (Chydoridae) of the world. Guides to the Identification of the Microinvertebrates of the Continental Waters of the World. SPB Academic, Amsterdam

Stearns SC (1989) The evolutionary significance of phenotypic plasticity. BioScience 39:436-445. https://www.jstor.org/stable/1311135

Thurman EM (1985) Organic geochemistry of natural waters. Springer, Dordrecht

Timofeyev MA, Wiegand C, Burnison BK, Shatilina ZM, Pflugmacher S, Steinberg CEW (2004) Impact of natural organic matter (NOM) on freshwater amphipods. Sci Total Environ 319:115-121. https ://doi.org/10.1016/S0048-9697(03)00444-3

Townsend SA, Boland KT, Wrigley TJ (1992) Factors contributing to a fish kill in the Australian wet/dry tropics. Water Res 26:10391044. https://doi.org/10.1016/0043-1354(92)90139-U

Tuljapurkar S (1990) Delayed reproduction and fitness in variable environment. PNAS 87:1139-1143. https://doi.org/10.1073/ pnas.87.3.1139

Vitale CM, Di Guardo A (2020) A review of the predictive models estimating association of neutral and ionisable organic chemicals with dissolved organic carbon. Sci Total Environ 666:1022-1032. https://doi.org/10.1016/j.scitotenv.2019.02.340

Weyhenmeyer GA, Muller RA, Norman M, Tranvik LJ (2016) Sensitivity of freshwaters to browning in response to future climate change. Clim Change 134:225-239. https://doi.org/10.1007/s 1058 4-015-1514-z

Williamson CE, Morris DP, Pace ML, Olson OG (1999) Dissolved organic carbon and nutrients as regulators of lake ecosystems: Resurrection of a more integrated paradigm. LimnolOceanogr 44:795-800. https://doi.org/10.4319/lo.1999.44.3_part_2.0795

Winfree R, Fox JW, Williams NM, Reilly JR, Cariveau DP (2015) Abundance of common species, not species richness, drives delivery of a real-world ecosystem service. EcolLett 18:626-535. https ://doi.org/10.1111/ele.12424

Yang Y (2007) Prediction/Estimation with simple linear models: is it really that simple? Economet Theor 23:1-36. https://www.jstor .org/stable/4126565

Publisher's Note Springer Nature remains neutral with regard to jurisdictional claims in published maps and institutional affiliations. 